\title{
Group Mentoring and Professionalism: a Programme Evaluation
}

\section{Authors}

ANN RITCHIE

Ebsco Australia and New Zealand

PAUL GENONI

Curtin University of Technology

In 1996 Ann Ritchie and Paul Genoni established the Group Mentoring Programme for graduate librarians as an initiative of the Western Australian Branch of the Australian Library and Information Association.

In addition to practical experience in individual and group mentoring, the authors have researched and evaluated mentoring programmes, published and presented internationally on the topic, and developed a workshop ('How to set up a facilitated group mentoring programme). They recently co-authored My Mentoring Diary, a learning journal for mentoring programme participants.

Ann Ritchie, B.App.Sci (Information and Library Studies), Grad.Dip. (Health Promotion), M.Sc., is a Database Consultant with EBSCO Information Services.

Paul Genoni, B.A., Grad.Dip. (Information and Library Studies), M.A., Ph.D., is a lecturer at Curtin University of Technology. 


\begin{abstract}
This evaluative research represents the first report in the literature to date in which a group mentoring programme has been evaluated using a quasi-experimental research design. Results indicated that the programme was effective in one domain of professionalism, the main outcome variable; and that career-development outcomes were significantly higher in programme participants. In addition to the previously established functions of mentoring (career and psychosocial development), the research suggests that the conceptual basis of mentoring should be expanded to include the function of professionalism. This has implications for both the practical aspects of mentoring programme development and for future evaluative research. Data were collected by means of pre- and post-test questionnaires and analysed by multiple regression analysis.
\end{abstract}

This paper provides a summary of the short-term evaluation of the programme; a complete account of the research can be found at:

http://john.curtin.edu.au/theses/public/adt-WCU20000321.120943/

\title{
Keywords
}

Group mentoring; professional socialisation; career development; psychosocial development; transitional stages; librarianship. 
For many years, mentoring has been understood as a means of supporting individuals through difficult career transitions. As a result organisations have taken steps to develop and manage formal mentoring programmes with a view to matching and assigning mentors to protégés, and thereafter supporting the mentoring relationship.

There are many examples of various types of formal mentoring programmes which have been developed to facilitate transitional career phases: entering tertiary education (Twomey, 1991), undertaking a programme of graduate study (Bowman, Bowman \& Delucia, 1990), starting work in a new professional career (Boyle \& Boice, 1998; Genoni \& Ritchie, 1996; Reiman, Bostick, Lassiter \& Cooper, 1995) and moving to a higher level in an organization (Ibarra, 2000; Bartunek, Kram, Coffey, Lenn, Moch \& O’Neill, 1997). The paucity of empirical and evaluative research of mentoring programmes has, however, been identified by Daresh (1995) and Chao (1997); and Gibb (1999) noted that there has been little theoretical analysis of the area.

This paper uses the results from evaluative research conducted with the participants in a group mentoring programme, to provide evidence of the value of this particular type of mentoring in supporting an individual's emerging professional identity. As a result of this outcome, the paper suggests developmental changes to the theoretical foundations of mentoring to augment the functions of mentoring established by previous research.

\section{FUNCTIONS OF MENTORING}

As a result of their qualitative research into the characteristics of formal mentoring relationships in organizations, Kram and Isabella (1985: 111) described the following functions and roles of mentoring:

Mentors provide young adults with career-enhancing functions, such as sponsorship, coaching, facilitating exposure and visibility, and offering challenging work or protection, all of which help the younger person to establish a role in the organization, learn the ropes, and prepare for advancement. In the psychosocial sphere, the mentor offers role modeling, counseling, confirmation, and friendship, which help the young adult to develop a sense of professional identity and competence.

Thus, in Kram and Isabella's typology, the 'career-enhancing functions' that occur in a mentoring relationship are focused on the organizational context; that is, they enhance an individual's capacity to win jobs, to make progress in the organization, and to develop skills which are necessary to satisfactory work-place performance and promotion. The 'psychosocial functions' are those which support an individual's sense of self worth and belief in their capacity to work effectively in their chosen profession.

Kram and Isabella's description of these two broad functions of mentoring has been widely influential on subsequent researchers. Later research indicates that:

- significant outcomes in the psychosocial functions but not in the career functions of 
mentoring can be expected in the first six months of a mentoring relationship (Noe, 1988);

- during the first year of an individual mentoring relationship the levels of both psychosocial and career support are at their lowest (Chao, 1997);

- higher levels of job-satisfaction (psychosocial adjustment) can be expected after one year in an individual mentoring relationship (Seibert, 1999).

\section{GROUP MENTORING}

As interest has grown in formal mentoring programmes as a means of enabling key transitional career phases, the mentoring paradigm has been re-evaluated and recast in innovative ways. Increasingly it has been understood and demonstrated that there are models for providing individuals with the desired career and psychosocial support which do not depend on the classical mentor-protégé dyad. In particular, research has pointed to the value of peer mentoring (Kram \& Isabella, 1985; Holbeche, 1996) in which a reciprocal mentoring function is provided by individuals with the same or similar professional status; and group or co-mentoring (Reiman, Bostick, Lassiter \& Cooper, 1995; Dansky, 1996; Genoni \& Ritchie, 1996; Challis, Mathers, Howe \& Field, 1997; Bartunek et al., 1997), in which the mentoring function is supplied by a more or less tightly constructed group of professional colleagues.

Group mentoring is a relatively new concept, and has been incompletely defined and poorly represented in the literature to date. In the broadest sense, the term 'group mentoring' has been used to describe a function of professional associations in which the career development of members of that professional group is influenced by the group's exertion of 'social norms and roles' (Dansky, 1996: 6). In a narrower sense, Reiman et al. (1995) described a 'support group' model which aimed to incorporate the stress-reduction benefits of small group meetings with the advantages of individual mentoring for a cohort of newly qualified professionals.

A third variation has been described as a 'co-mentoring group' model, in which a small group of professionals led by a peer facilitator has been shown to have the potential to provide an acceptable structure for a successful continuing professional development strategy (Challis et al., 1997: 25).

Genoni and Ritchie (1996) explored the relationship between group mentoring and more traditional forms of mentoring. Drawing on the exploratory research of Kram and Isabella (1985), the literature to date and the results of their practical experience in mentoring programme management, they formulated the three essential characteristics of mentoring in a professional environment. These are that mentoring is:

1. a two-way learning relationship which draws upon the knowledge and wisdom of suitably experienced practitioners;

2. designed to fulfil two broad purposes of career and psychosocial development, with the specific goals of the relationship being determined by the individuals involved; and 
3. a relationship which develops over time, i.e., there is more than just a short-term or passing interest on the part of the mentor in the protégés, and the relationship passes through a series of developmental stages.

These essential characteristics of mentoring relationships can be applied and practised within a group, and thus group mentoring is a process in which the functions and roles of mentoring are carried out by the leaders and participants in a group environment.

It is important to note that the concept of the 'group' as it was applied in the Group Mentoring Programme under study differed significantly from that to which Dansky (1996) referred. Dansky's concept of 'group mentoring' relied on two processes - the normative influence of the members of the whole professional group being exerted on the individual and the individual's gradual imbibing and adoption of the norms and values of the professional organization. In the case of the Group Mentoring Programme described in this article, a small and homogenous subset of the whole professional organization was created for the express purpose of using structured, mentoring-based learning as a means of facilitating the transition of new graduates into the profession.

Although no evaluative research has been conducted on a facilitated group mentoring programme similar to that which is the focus of this report, there have been studies which point to the value of peer group support, peer activities and peer mentoring. These have been conducted in the following areas:

- professional socialization of new graduates (the value of group meetings as part of an individual mentoring programme) (Boyle \& Boice, 1998);

- the development of a professional identity among masters students (the effectiveness of peer activities in the informal curriculum) (Fidler, 1995);

- professional and personal learning for general practitioners (the value of peer activities with a group leader and co-mentoring in small groups) (Challis et al., 1997);

- stress reduction for graduate students (the influence of peer mentoring in pairs) (Bowman et al., 1990);

- stress prevention and increased psychosocial wellbeing (benefits to individuals who acted as peer mentors of university students, but no significant psychosocial benefits to the peer group participants) (Twomey, 1991).

\section{AIMS AND OBJECTIVES OF THE RESEARCH}

The purpose of the current evaluation was to assess the effectiveness of a group mentoring programme, the main aim of which was to facilitate the transition of new graduates in librarianship into their profession. In this context, to 'facilitate' meant to make the movement or change more effectively (in terms of professional socialization) and more easily (by ameliorating sources of stress). It was emphasized from the beginning that the objectives of the Programme were based on the achievement of continuing professional development outcomes, not simply helping the new graduates to get a job. It was posited that mentoring, in this case implemented through a formally structured and facilitated group programme, would have a positive effect on professional socialization and psychosocial health. 
Du Toit (1996, 164-165) defined professional socialization as: “a developmental process of adult socialization. Not only does it involve the recognition of an assumed identity by the outside world; it also involves individuals' recognition of the identity within themselves and the non-deliberate projection of themselves in its terms - referred to as internalisation.” Thus in its broadest sense, the Group Mentoring Programme's purpose related to professional socialization - the transition of new graduates into the profession and the development of a professional identity, which would be recognised both by the larger professional group and by the individuals themselves.

The main objectives of the research were:

1. to conduct an impact (short-term) evaluation of the programme to determine the extent to which the Group Mentoring Programme provided professional socialization, career and psychosocial outcomes; and

2. to explore and develop the theoretical and conceptual bases of mentoring.

As the primary objective of the research was to conduct an impact evaluation of the Programme, and the main aim of the Programme was to facilitate the transition of new graduates into a profession, the principle research question addressed was stated as follows:

To what extent can the mentoring activities of the group be used to predict the professional socialization and professional identity of new graduates?

In the process of addressing this primary research question, the second objective of the research i.e., to explore and develop the theoretical and conceptual bases of mentoring, was also carried out. Thus a second research question incorporating the risk factors or indicator variables identified in the literature on mentoring was stated as follows:

To what extent can the mentoring activities of the group be used to predict outcomes in the career and psychosocial domains for new graduates?

Based on the two research questions the following hypotheses were formulated:

H1: There is a significant difference in professional identity of new graduates who participated in the Group Mentoring Programme compared with those who did not participate in the Programme.

H2: There is a significant difference in career and psychosocial outcomes for new graduates who participated in the Group Mentoring Programme compared with those who did not participate in the Programme.

\section{DESCRIPTION OF THE GROUP MENTORING PROGRAMME}


The Group Mentoring Programme which formed the basis of the study was conducted under the auspices of the Australian Library and Information Association (ALIA). The programme was devised, implemented and facilitated by the authors, both professional librarians with managerial, teaching and mentoring experience.

It was recognised that the transition from graduate to first professional position was a critical developmental stage in which the help of a mentor could be very beneficial. An individual mentoring programme had already been established by ALIA three years prior to the implementation of the group programme. Interest in the individual programme had been shown from new and recent graduates, as well as from current students. It had been noted, however, that many newer graduates were reluctant to put themselves forward as potential protégés. It had also been observed that graduating students often found support amongst their peers, and it was therefore believed that the mentoring model could be adapted in a way which would draw upon, strengthen and expand this existing network of support.

It was posited that within a group mentoring programme the mentoring functions and roles of conventional, individual mentoring relationships could be shared by the group's facilitators (who would perform a group facilitation and 'learning leader' role, as well as acting as individual mentors for participants in the group) and through the development of peer mentoring relationships within the group. It was anticipated that this peer mentoring would occur through a natural selection process among group members. Thus in this type of mentoring no assignment of pairs was necessary.

The initial group mentoring programme was conducted in 1996, and the programme which was evaluated was conducted in 1997. The formal meetings comprised eleven, two-hour, monthly sessions in which the Group's learning objectives were addressed. In the interim the two facilitators (acting in their individual mentoring roles) were available for small group and one-to-one mentoring sessions.

The facilitators were responsible for promoting the programme, enrolling the participants, conducting the first meeting in which the learning objectives were established, acting as mentors to individuals in the group, overseeing the meetings, ensuring that the objectives of the programme were met in ways which incorporated mentoring activities, and conducting the evaluation.

The formal objectives of the Group Mentoring Programme were:

1. to provide opportunities for continuing professional development in librarianship;

2. to facilitate the sharing of information, ideas and feedback in a supportive environment;

3. to encourage the application of the theory learnt in formal education to practical issues and experiences;

4. to assist participants to develop and achieve their career plans;

5. to provide opportunities for participants to learn and practise mentoring and peer support skills; 
6. to encourage the development of leadership roles within the group;

7. to introduce the participants to ALIA committees, special interest groups and networks.

The participants were encouraged to take responsibility for organising and leading a session of their choice. Learning objectives and strategies were discussed before each session with the leaders of that meeting, and feedback on their performance was provided by the facilitators. Librarians and other professionals were invited to be guest speakers at meetings, and often the meetings were held at the practitioner's library. A process evaluation was conducted mid-way through the year to assess participants' satisfaction and learning, and the learning objectives were re-prioritised accordingly.

One of the Programme's formal objectives was to provide opportunities for participants to learn and practise mentoring and peer support skills. Mentoring skills were modelled by the group facilitators, and deliberate strategies were set in place for mentoring to occur on a peer level. For this reason training in the skills of mentoring, such as giving and receiving feedback, supervision, goal setting, career planning and professional coaching, was incorporated into the programme.

In the career-related sphere, the facilitators encouraged the sharing of information about opportunities for exposure, sponsorship and challenging projects. Job introductions occurred among peers as well as through the professional networks. Membership of ALIA was a pre-requisite for joining the Group and the facilitators also encouraged the participants to join the professional association's special interest groups and committees, and to participate in professional development activities.

In the psychosocial sphere, the facilitators offered support, individual coaching and counselling. The counselling role was used mainly as a mechanism for clarifying and monitoring individual objectives and providing feedback to help the participants to learn from their own experience. Role modelling by the facilitators occurred in a less formalised way. Friendships amongst group members were also developed.

\section{METHODOLOGY}

A quasi-experimental research design was used to evaluate the outcomes of the Programme. The experimental group was self-selected, and the remainder of the total population of approximately eighty graduating library students, from two universities in Perth, Western Australia, was available for inclusion in the comparison group. No randomization occurred. The study was designed prospectively and the data were collected by means of pre- and post-tests conducted on the experimental group (E: 23 subjects) and two comparison groups, a group who did not have a current mentor (C1: 18 subjects) and a group who had an individual mentor during the year of the study (C2: 22 subjects).

\section{Survey Instruments}


The data for all the variables in this study i.e., demographic information, professionalism, career and psychosocial development, sources of stress, and experiences of mentoring functions, were collected by means of pre- and post-test questionnaires. These questionnaires included the various scales which were used to measure the main outcome variables - professionalism, career and psychosocial development. Because the outcome measures were calculated by subtracting the pre-test scores from the post-test scores they were designated: Professional Identity Index (Difference), Career Index (Difference) and Psychosocial Index (Difference).

\section{Professionalism}

Professionalism was measured by Hall's Professionalism Scale (revised version, Snizek, 1972) and used as the basis for the construction of the Professional Identity Index (Difference). The five dimensions of professionalism identified by Hall were: use of the professional organization as a major referent; belief in public service; belief in selfregulation; having a sense of 'calling' to the field; autonomy.

Hall's Professionalism Scale was chosen for a number of reasons. As a measuring instrument its reliability and validity had already been established, and librarians were one of the groups who were included in Hall's development and validation of the scale. The instrument had been used in other studies where professionalism was measured as an outcome of mentoring and also on a study population of masters students in librarianship.

\section{Career and Psychosocial Development}

As described previously, the two domains generally ascribed to the mentoring construct relate to career and psychosocial development. In order to measure these two outcomes the research used indexes of career and psychosocial development which had been devised and pilot-tested in the 1996 Group Mentoring Programme.

Career development activities were measured quantitatively and self-reported by the subjects. Items included were: preparation of a curriculum vitae and having career objectives to achieve for the year, membership of the professional association, committee membership of the association's special interest groups or sections, attending meetings and continuing education events. These were devised to indicate an index of activities that would lead to successful career outcomes.

Psychosocial development was indicated by self-assessment measures which related to the subjects' perceptions of themselves as belonging to the profession and participating in professional activities, being involved in their peer support network, having a belief in their own knowledge and ability to apply their skills in the workplace, and being aware of issues affecting their area of work and their profession.

\section{Mentoring Functions}

To confirm that mentoring activities had actually occurred within the experimental group, Noe’s Mentoring Activities questionnaire (Noe, 1988: 468-469), a validated measuring 
instrument, was administered at the conclusion of the programme to the experimental group only.

\section{Statistical analyses}

Chi-square tests and one-way anovas were used to ascertain whether there were any significant differences between the groups at the pre-test stage. Multiple regression analyses were used to identify significant predictor variables and to test whether there were significant differences between the experimental group and the comparison groups on the outcome variables i.e., differences between the subjects pre- and post-test scores in the Professionalism Scale, including the five domains of professionalism, and the Career and Psychosocial Indexes.

Regression analysis was used and this controlled for any differences on the outcome variables which existed between the groups at the pre-test stage as well as any possible differences due to other factors. These analyses are equivalent to repeated measures anova. For ease of analysis and for comparability of results, stepwise regression procedures were used in preference to anova procedures. All the necessary tests with regard to assumptions for regression analyses were carried out.

\section{RESULTS}

\section{Hypothesis one}

\section{Professionalism}

There was partial support for the research hypothesis H1: that there is a significant difference in professional identity of new graduates who participated in the Group Mentoring Programme compared with those who did not participate in the Programme. Although regression analysis for the Professional Identity Index (Difference) did not show a significant difference between the treatment groups, partial support for $\mathrm{H} 1$ was found when each of the five domains of professionalism was tested by multiple regression analyses: a significant difference between the experimental and C1 groups in the domain of having a sense of 'calling' was revealed.

\section{Having a sense of 'calling' to the field}

As shown in Table 1, the 'calling' domain revealed significant differences between the experimental group and one of the comparison groups. The p-value resulting from the stepwise regression was .017 in this domain. The Table also shows that membership of one of the professional association's committees was a significant predictor variable in the model $(\mathrm{p}=.035)$. Other independent variables entered stepwise into the model which did not show a significant difference were: age, qualification, gender and previous mentoring experience. 
Table 1: Regression Model: 'Calling' Index (Difference)

\begin{tabular}{|c|c|c|c|c|}
\hline \multirow[b]{2}{*}{ Variables } & \multicolumn{2}{|c|}{$\begin{array}{l}\text { Unstandardized } \\
\text { Coefficients }\end{array}$} & \multirow[b]{2}{*}{ t-value } & \multirow[b]{2}{*}{ p-value } \\
\hline & B & Std. Error & & \\
\hline (Constant) & 11.189 & 1.763 & 6.346 & .000 \\
\hline $\begin{array}{l}\text { Calling } \\
\text { (Pre-test) }\end{array}$ & -.578 & .097 & -5.959 & .000 \\
\hline $\begin{array}{l}\text { Experimental } \\
\text { vs } \mathrm{C} 1\end{array}$ & -2.020 & .824 & -2.451 & .017 \\
\hline $\begin{array}{l}\text { Experimental } \\
\text { vs C2 }\end{array}$ & -.608 & .766 & -.795 & .430 \\
\hline $\begin{array}{l}\text { Committee } \\
\text { membership }\end{array}$ & -2.341 & 1.084 & -2.159 & .035 \\
\hline
\end{tabular}

Adjusted R square $=.417$

Significance in the 'calling' domain indicated that the Group Mentoring Programme participants had increased their belief in their profession as a vocation, that they thought of their chosen field of work as more than just an occupation or a way of earning a living. For the comparison group (C1) who did not have a current mentor, this sense of a calling to the profession had declined. Having a sense of calling to a professional field has been described as one of the main differences between a profession (or a vocation) and a job. It may have been that the Group Mentoring Programme functioned as a first step in raising awareness of this distinction. As the main purpose of the Programme was to 'facilitate the transition of new graduates into the profession', it can be concluded that this key objective in educating new graduates about this aspect of professionalism was achieved through the group mentoring process.

No significant results were found in the remaining four domains in the Professionalism Scale ('use of the professional organization as a major referent', 'belief in public service', 'belief in self-regulation' and 'autonomy').

\section{Career and psychosocial development}

Regression analysis revealed that there was no significant difference between the treatment groups on the dependent variable, the Professional Identity Index (Difference). Independent variables entered stepwise into the model were: treatment condition (group), Professional Identity Index (pre-test), age, qualification, gender, previous mentoring experience, Career Index (Difference), and Psychosocial Index (Difference). The pre-test Professional Identity Index was included to control for any differences (between subjects) that existed from the outset on this variable.

When all the groups were taken into account, there were, however, three significant predictors of the dependent variable: the Professional Identity Index (pre-test), the Career Index (Difference), and the Psychosocial Index (Difference). Table 2 shows that the Career Index (Difference) and Psychosocial Index (Difference) which had been constructed to indicate achievement of sub-objectives (or contributory risk factors) 
related to the two domains of mentoring had a significant effect on the dependent variable (the development of a professional identity).

Table 2: Regression Model: Professional Identity Index (Difference)

\begin{tabular}{|c|c|c|c|c|c|}
\hline \multirow[b]{2}{*}{ Variables } & & \multicolumn{2}{|c|}{$\begin{array}{c}\text { Unstandardized } \\
\text { Coefficients }\end{array}$} & \multirow[b]{2}{*}{ t-value } & \multirow[b]{2}{*}{ p-value } \\
\hline & & B & Std. Error & & \\
\hline & (Constant) & 42.670 & 8.806 & 4.845 & .000 \\
\hline & $\begin{array}{l}\text { Professional } \\
\text { Identity Index } \\
\text { (Pre-test) }\end{array}$ & -.475 & . 104 & -4.565 & .000 \\
\hline & $\begin{array}{l}\text { Career Index } \\
\text { (Difference) }\end{array}$ & -2.455 & .767 & -3.199 & .002 \\
\hline & $\begin{array}{l}\text { Psychosocial } \\
\text { Index } \\
\text { (Difference) }\end{array}$ & 1.483 & .500 & 2.965 & .004 \\
\hline
\end{tabular}

Adjusted R square $=.332$

The positive coefficient for the Psychosocial Index (1.483) indicated that an increase in this score was associated with an increase in the Professional Identity Index. That is, professional identity (the outcome variable) was shown to be affected by the psychosocial development of new graduates. An increase in scores on this attitudinal scale (measuring the individual's perception of and belief in themselves) was significantly related to an increase in professional identity.

The negative coefficient for the Career Index (-2.455) indicated an inverse relationship between the Career Index and the Professional Identity Index. That is, an increase in the Career Index was associated with a decrease in the Professional Identity Index.

Career development items provided an index of activities that would lead to successful career outcomes. The inverse relationship between career development activities and professional identity suggested that where an individual focused on career outcomes and activities, the development of a professional identity was not enhanced (at least not in the first year of a new graduate's career). Thus although career development and professional development are related, in the short-term and particularly for new graduates, an increase in one implies a lack of development in the other.

Thus it can be inferred from these results that it would be beneficial for continuing professional development programmes (including mentoring programmes) which aim to promote professional socialization and the development of a professional identity to incorporate specific psychosocial development strategies (as these are likely to be associated with an increase in an individual's professionalism). As career development activities are likely to inhibit professional socialisation it may be beneficial to clearly differentiate these from psychosocial development activities.

\section{Hypothesis two}

There was partial support for the research hypothesis H2: that there is a significant 
difference in career and psychosocial outcomes for new graduates who participated in the Group Mentoring Programme compared with those who did not participate in the Programme. Regression analysis revealed a significant difference between the treatment groups in the career domain but not in the psychosocial domain. That is, the mentoring activities of the experimental group had a positive effect on career outcomes, but not on psychosocial outcomes. Noe's Mentoring Activities questionnaire validated that mentoring activities had taken place in the experimental group, who were participants in the Group Mentoring Programme.

\section{Career and psychosocial development}

For the Career Index (Difference), treatment condition was a significant predictor in the model, indicating that the mentoring activities of the experimental group had made a difference to career outcomes (see Table 3). This was significant when the experimental group was compared with both comparison groups i.e. C1: those who did not have a current mentor, and C2: those who had a current, individual mentor. Other variables which could be incorporated into the model using stepwise procedures were Career Index (pre-test) and gender (p-value $=.036$ ). As it had been established that there was a significant difference between the experimental group and the C2 group on the Career Index (pre-test), this was entered into the regression model in order to control for this difference between the groups at the pre-test stage.

\section{Table 3: Regression Model: Career Index (Difference)}

\begin{tabular}{|c|c|c|c|c|}
\hline \multirow[b]{2}{*}{ Variables } & \multicolumn{2}{|c|}{$\begin{array}{c}\text { Unstandardized } \\
\text { Coefficients }\end{array}$} & \multirow[b]{2}{*}{ t-value } & \multirow[b]{2}{*}{ p-value } \\
\hline & B & Std. Error & & \\
\hline (Constant) & 1.654 & .476 & 3.477 & .001 \\
\hline $\begin{array}{l}\text { Career Index } \\
\text { (Pre-test) }\end{array}$ & -.560 & .104 & -5.396 & .000 \\
\hline $\begin{array}{l}\text { Experimental } \\
\text { vs } \mathrm{C} 1\end{array}$ & -1.600 & .259 & -6.174 & .000 \\
\hline $\begin{array}{l}\text { Experimental } \\
\text { vs C2 }\end{array}$ & -1.100 & .246 & -4.467 & .000 \\
\hline Gender & .920 & .428 & 2.151 & .036 \\
\hline
\end{tabular}

Adjusted R square $=.464$

There was an inverse relationship between the experimental group and both comparison groups (indicated by the negative coefficients for the treatment group variables in Table 3). From the following Table 4, which compares the means for these groups for the Career Indexes, it can be seen that this coefficient meant that the increase in scores for the experimental group was associated with a decrease in the C1 group's scores and a smaller increase in the C2 group's scores. Thus the career development activities were significantly higher in the experimental group. 
Table 4: Mean Scores for Career Indexes by Treatment Group

\begin{tabular}{|c|c|c|c|c|}
\hline $\begin{array}{l}\text { Treatmen } \\
\text { Groups }\end{array}$ & & $\begin{array}{l}\text { Career } \\
\text { Index } \\
\text { (Pre-test) }\end{array}$ & $\begin{array}{c}\text { Career } \\
\text { Index } \\
\text { (Post-test) }\end{array}$ & $\begin{array}{c}\text { Career } \\
\text { Index } \\
\text { (Difference) }\end{array}$ \\
\hline \multirow{4}{*}{$\begin{array}{l}\mathrm{C1} \\
(\mathrm{N}=18)\end{array}$} & Mean & 1.9711 & 1.7401 & -.2309 \\
\hline & $\begin{array}{l}\text { Std. } \\
\text { Deviation }\end{array}$ & 1.1072 & 1.1063 & .8825 \\
\hline & Minimum & .00 & .00 & -2.28 \\
\hline & Maximum & 3.69 & 3.41 & 1.22 \\
\hline \multirow{4}{*}{$\begin{array}{l}\mathrm{C} 2 \\
(\mathrm{~N}=22)\end{array}$} & Mean & 1.9640 & 2.2552 & .2911 \\
\hline & $\begin{array}{l}\text { Std. } \\
\text { Deviation }\end{array}$ & .8402 & .9560 & .9000 \\
\hline & Minimum & 1.00 & .06 & -1.61 \\
\hline & Maximum & 4.13 & 3.41 & 2.00 \\
\hline \multirow{4}{*}{$\begin{array}{l}E \\
(N=23)\end{array}$} & Mean & 2.7246 & 3.7740 & 1.0494 \\
\hline & $\begin{array}{l}\text { Std. } \\
\text { Deviation }\end{array}$ & 1.0766 & .7862 & 1.0342 \\
\hline & Minimum & .00 & 2.56 & -.78 \\
\hline & Maximum & 5.33 & 5.58 & 3.39 \\
\hline \multirow{4}{*}{$\begin{array}{l}\text { Total } \\
(\mathrm{N}=63)\end{array}$} & Mean & 2.2437 & 2.6625 & .4188 \\
\hline & $\begin{array}{l}\text { Std. } \\
\text { Deviation }\end{array}$ & 1.0591 & 1.2762 & 1.0692 \\
\hline & Minimum & .00 & .00 & -2.28 \\
\hline & Maximum & 5.33 & 5.58 & 3.39 \\
\hline
\end{tabular}

The career outcome measure showed a significant difference when the experimental group was compared to both comparison groups (see Table 3). For the Group Mentoring participants, the year of transition had a very strong career focus. The Group Mentoring participants also gave priority in the formulation and prioritisation of their learning objectives to those objectives which related to getting a job (for example, the learning objectives for the first four months of the Programme focused on preparing a curriculum vitae, addressing selection criteria, interviewing skills, exploring alternative methods of getting a job).

In this one-year programme, the population of new graduates was more focused on achieving career outcomes than psychosocial benefits. Related to this career focus, it may have been the group mentoring format itself which affected the amount of emphasis placed on desired outcomes. In a one-to-one mentoring relationship there is likely to be a greater degree of comfort and more freedom to express personal concerns than in a group discussion. In the first year of a group mentoring programme, when the group itself was going through the initial phase of group development, it is logical to assume that levels of trust and confidence which would facilitate the sharing of more personal psychosocial concerns in the group would not yet have developed.

\section{DISCUSSION}

The results of this evaluative research in the area of group mentoring extend what is 
known about the short-term outcomes of group mentoring in the following ways:

1. A one-year group mentoring programme is not effective as a single strategy for the development of a professional identity among new graduates;

2. Group mentoring has a significant effect on the development of a professional identity in the domain of a new graduate's sense of 'calling' to the field;

3. Group mentoring has significant benefits for new graduates in the first year of a mentoring programme in the career development sphere, but not in the psychosocial sphere.

The research also found that with regard to the process of professional socialization:

4. Psychosocial development activities have a significant effect on the development of a professional identity among new graduates;

5. Career development activities have a significant effect on the development of a professional identity among new graduates, but this is an inverse relationship.

It is suggested by these results that Kram and Isabella's influential dichotomy of 'career-enhancing functions' and 'psychosocial functions' is too restrictive and requires development in order to reflect the complex nature and varieties of learning and development that occur within mentoring relationships. The current research indicates that there is a third aspect of learning and development that also occurs, which may be referred to as the 'professionalism function', and that this is different from both the career and psychosocial development which occurs amongst new graduates.

\section{Professionalism function of mentoring}

The professionalism function includes some aspects of both of these other functions, but relates not to an individual's relationship to their job ('career') or self ('psychosocial'), but to the process of professional socialization. In the case of new graduates this encompasses their exposure to and acceptance of their own professional identity both by themselves and by the wider professional network or group to which they seek entry. In fulfilling this professionalism function, mentoring introduces the protégés to and reinforces their understanding of the various standards of practice, conduct and participation which are underpinned by a set of professional values, and constitute acceptable norms within a profession. On a practical level, mentoring promotes the protégé's learning and development by encouraging or sponsoring involvement in professional activities. There is thus a direct relationship between the professionalism function and the roles of mentoring which facilitate the individual's 'continuing professional development'.

Mentoring relationships exist within a broader framework of mentoring programme design. As previously outlined in the three essential characteristics of mentoring, 
mentoring relationships are primarily learning relationships; the specific goals of any mentoring relationship need to be formulated by the individuals involved; and mentoring relationships develop and they are long-term.

The specific goals can be short-term and/or long-term goals, and must be compatible with the overall aim of the programme. These goals are most often achieved through mentoring activities. These types of activities are described by the various roles of mentoring, e.g. coach, sponsor, counselor, role model, friend. The professionalism function may be carried out through the same or similar roles, but there may be additional roles of mentoring which are unique to the professionalism function.

It is likely that the professionalism function will also relate to the overall aim/purpose of the programme, and may be more likely to be emphasised in a mentoring programme which is conducted by a professional body. This is not the same as programmes within organisations which may have a career development purpose, or more socially oriented programmes which may operate more in the psychosocial sphere.

In seeking to enhance the professionalism function of mentoring, it is suggested that mentors and protégés should be prepared to overcome any sense of 'exclusivity' in their relationship, and instead use it as a source from which to explore the various forms of support available in the wider professional group. Ibarra (2000: 155), having explored the role of partners as mentors in large professional service firms, concluded that the purpose of formal mentoring programmes should be reconsidered - that as well as performing the traditional roles of coach, friend and supporter, mentors should 'steer their protégés to a broad set of people and experiences'. According to the paradigm suggested by Ibarra, the mentor takes on a traditional mentoring role while also acting as a facilitator who encourages the protégés into other forms of support in the wider professional group. Similarly, Higgins \& Kram (2001) have recently explored the existence of 'developmental networks' drawn from a range of colleagues as a new means of conceptualising mentoring.

Also relevant is Gibb’s (1999: 1063-1064) attempt to devise a theoretical foundation for mentoring. Gibb offers the theory of 'communitarianism', which is founded on the principle that 'people act in a pro-social, virtuous way as they are bound by core values, established and maintained by virtue of being members of a community'. Although Gibb locates his discussion of communitarianism within the work-place, it is clear that the theory could include the community structure apparent within professional associations or groups, or indeed any forum with 'an existing strong "spirit of community" in the setting, a healthy civil society, or an aspiration to be a strong community' (1064). Gibb predicts the enhanced effectiveness of formal mentoring programmes which are implemented within 'strong communities' (1065), with the newcomer imbibing norms associated with the practice of their chosen profession.

\section{CONCLUSION}


This paper has proposed that the previously established dichotomy of mentoring outcomes into career and psychosocial functions does not adequately describe the full range of benefits derived by participants. The research reported above supports the introduction of a professionalism function which has outcomes and benefits which can be differentiated clearly from the career and psychosocial outcomes. Evidence accruing elsewhere also indicates that there are outcomes which can be said to indicate a third function which is described by the authors as the professionalism function. It is suggested that future research is needed to devise and/or develop instruments which test for outcomes in the area of professionalism. In addition, the roles of mentoring as they relate to the professionalism function require further exploratory research. 


\section{REFERENCES}

Bartunek, J.M., Kram, K.E., Coffey, R., Lenn, D.J., Moch, M.K., and O’Neill, H. (1997) "A group mentoring journey into the department chair role", Journal of Management Inquiry, Vol 6 No 4, pp 270-279.

Bowman, R. L., Bowman, V. E., and DeLucia, J. L. (1990) "Mentoring in a graduate counseling programme: students helping students", Counselor Education and Supervision, Vol 30 No 1, pp. 58-65.

Boyle, P., and Boice, B. (1998) "Systematic mentoring for new faculty teachers and graduate teaching assistants”, Innovative Higher Education, Vol 22 No 3, pp. 157-179.

Challis, M., Mathers, N.J., Howe, A.C., and Field, N.J. (1997) "Portfolio-based learning: continuing medical education for general practitioners - a mid-point evaluation”, Medical Education, Vol 31 No 1, pp. 22-26.

Chao, G. T. (1997) "Mentoring phases and outcomes", Journal of Vocational Behavior, Vol 51 no 1, pp. 15-28.

Dansky, K. H. (1996) “The effect of group mentoring on career outcomes”, Group and Organization Management, Vol 21 No 1, pp. 5-21.

Daresh, J. C. (1995) "Research base on mentoring for educational leaders: what do we know?”, Journal of Educational Administration, Vol 33 No 5, pp. 7-16.

Du Toit, D. (1996) "A sociological analysis of the extent and influence of professional socialization on the development of a nursing identity among nursing students at two universities in Brisbane, Australia”, Journal of Advanced Nursing, Vol 21 No 1, pp. 164171.

Fidler, L. M. (1995), Interactions with Faculty, Peers and Practitioners in the Informal Curriculum as Predictors of Professional Identity. Unpublished PhD, University of Wisconsin.

Genoni, P. W., and Ritchie, A. (1996), "Mentoring as continuing professional development: the ALIA (WA) Group Mentoring Programme", in Reading the future: Proceedings of the Biennial Conference of the Australian Library and Information Association World Congress Centre, Melbourne Australia 6-11 October 1996, Australian Library and Information Association, Melbourne, pp. 187-195.

Gibb, S. (1999). "The usefulness of theory: a case study in evaluating formal mentoring schemes”, Human Relations, Vol 52 No 8, pp. 1055-1075. 
Higgins, M. C., and Kram, K. E. (2001) "Reconceptualizing mentoring at work: a developmental network perspective”, Academy of Management Review, Vol 26 No 2, pp. 264-288.

Holbeche, L. (1996) "Peer mentoring: the challenges and opportunities", Career Development International, Vol 1 No 7, pp. 24-27.

Ibarra, H. (2000) "Making partner: a mentor's guide to the psychological journey" Harvard Business Review, Vol 78 No 2, pp. 146-155.

Kram, K. E., and Isabella, L. (1985) "Mentoring alternatives: the role of peer relationships in career development", The Academy of Management Journal, Vol 28 No 1, pp. 110-132.

Noe, R. A. (1988) "An investigation of the determinants of successful assigned mentoring relationships”, Personnel Psychology, Vol 41, pp. 457-479.

Reiman, A. J., Bostick, D., Lassiter, J., and Cooper, J. (1995) “Counselor- and teacherled support groups for beginning teachers: a cognitive-developmental perspective”, Elementary School Guidance and Counseling, Vol 30 No 2, pp. 105-17.

Ritchie, A. (1999) Group Mentoring and the Professional Socialization of Graduate Librarians: A Programme Evaluation, Unpublished M.Sc., Curtin University of Technology. http://john.curtin.edu.au/theses/public/adt-WCU20000321.120943/

Seibert, S. (1999) "The effectiveness of facilitated mentoring: a longitudinal quasiexperiment”, Journal of Vocational Behavior, Vol 54 No 3, pp. 483-502.

Snizek, W. E. (1972) “Hall's professionalism scale: an empirical reassessment”, American Sociological Review, Vol 37, pp. 109-114.

Twomey, J. L. (1991) Academic Performance and Retention in a Peer Mentor Programme at a Two-year Campus of a Four-year Institution (Research Report ED331552): New Mexico State University, Alamogordo. 